Short communication

2020 | Volume 8 | Issue 3 | Pages 100-103

ARTICLE INFO

Received

June 09, 2020

Revised

July 20, 2020

Accepted

July 23, 2020

Published

August 31, 2020

*Corresponding author Mohammad Azizur Rahman

E-mail

azizbmb@juniv.edu

Keywords

Hormonal profile

Normal cyclic breeding

Ovulation

Repeat breeding

Repeat breeding problems

How to cite

Rahman MA, Islam S, Alam J,

Uddin F, Alam M. Hormonal

profile study of Bangladeshi

crossbred dairy cows in

relation to repeat breeding. Sci

Lett 2020; 8(3):100-103
Open Access

\section{Hormonal Profile Study of Bangladeshi Crossbred Dairy Cows in Relation to Repeat Breeding}

\author{
Mohammad Azizur Rahman ${ }^{*}$, Sirajul Islam², Jahangir Alam ${ }^{1}$, \\ Forhad Uddin ${ }^{1}$, Morshed Alam ${ }^{1}$ \\ ${ }^{1}$ Department of Biochemistry and Molecular Biology, Jahangirnagar University, Savar, \\ Dhaka-1342, Bangladesh \\ 2 Bangladesh Livestock Research Institute, Regional Station, Baghabari, Sahajadpur, \\ Sirajgonj-6770, Bangladesh
}

\section{Abstract}

The repeat breeding condition affects both the fertility of cows and the economy of farmers and the nation. Normal levels of various biochemical constituents are indispensable for the normal functioning of various body systems of animals, including the reproductive system. The hormonal profile is an indicator of the reproductive status and aids in the prognosis and restoration of animal fertility. The present study explores the implication of four hormones (luteinizing hormone, follicle-stimulating hormone, human chorionic gonadotropin and prolactin) on the normal cycle breeding process of Bangladeshi normal cyclic cows and repeat breeder dairy cows. Among four hormones, the levels of luteinizing hormone and prolactin were significantly different between the normal cyclic cows and repeat breeder cows. The assessment of hormonal profile aids in ameliorating the repeat breeding conditions of the dairy cows. The findings of the present study could be applied in overcoming repeat breeding problems in dairy cows and thus, economic loss could be lessened. 


\section{Introduction}

Successful reproduction of dairy cattle depends on multiple factors, one of those is hormonal sufficiency. Hormones are signaling molecules, produced in endocrine glands and transported by the circulatory system to regulate biochemical and physiological activities of the target organs [1]. Hormones vary in structure, function and mode of function [1]. They play a vital role in milk production and maintenance of the normal reproductive cycle of all organisms, including dairy cows [2]. The reproductive capacity of dairy cows is an important issue from the economic point of view. Thus, factors affecting reproduction have received the utmost attention and a multitude of causes and effects have been recommended [3]. Among the grave concerns affecting the reproductive lives of dairy cows are repeat breeding syndrome (RBS) [4]. RBS refers to the failure of the cows in conception, though they undergo repeated breeding or mating. Usually, a repeat breeder (RB) cow is less than 10 years old and is free from palpable clinical abnormalities. Physiologically, it undergoes a normal estrous cycle and has no abnormal vaginal discharge. Often, it has calved at least once but has failed to conceive after at least three or more consecutive inseminations. Consequently, it leads the farmer to economic loss as its feeding provides no production or delayed conception as well as repeated insemination and treatment. Thus, identification of abnormalities triggering RBS and their amelioration is of paramount importance for successful dairy farming. Up to the present time, the identified abnormalities have been characterized into genetic, ovarian malfunction, infection and environmental. There has been a scarcity of studies regarding the plasma hormonal level of repeat breeder dairy cows. Considering these issues, the present study was designed to elucidate the hormonal profile of the Bangladeshi crossbred dairy cows in regards to the repeat breeding.

\section{Materials and methods}

\section{Study area}

Farm work was performed at the Baghabari milk shed area, Bangladesh. Laboratory analyses were performed at Bangladesh Livestock Research Institute (BLRI) and at the Department of Biochemistry and Molecular Biology, Jahangirnagar University, Bangladesh.

\section{Selection of animals, feeding and management}

Thirty crossbred dairy cows, under artificial insemination (AI), were selected. Uniform feeding and facilities were provided to them. The cows were fed with green grass/fodder and drank water ad libitum. A mobile ultrasound scanner was used for the constant monitoring of cows. Selected cows were preliminarily divided into two groups: normal cyclic cows (NC, bred and conceived normally within three artificial inseminations during their estrous cycles) and repeat breeder cows (RB, cows that did not conceive after three or more artificial inseminations during their estrous cycles). Based on heating and non-heating criteria, both $\mathrm{NC}$ and $\mathrm{RB}$ group cows were further classified into two groups: $\mathrm{NC}$ heated $(\mathrm{NCH})$ cows and $\mathrm{NC}$ non-heated $(\mathrm{NCN})$ cows; RB heated $(\mathrm{RBH})$ cows and $\mathrm{RB}$ non-heated (RBN) cows.

\section{Synchronization of dairy cows}

The normal 21-day estrous cycle of cows was manipulated for breeding at the same time called synchronization. Following the Ovsynch protocol [5], the RB cows were synchronized with the treatment of gonadotrophin-releasing hormone $(\mathrm{GnRH})$ and prostaglandin F2 alpha (PGF2 $\alpha$ ) (Fig. 1). Prostaglandin (PG) treatment was performed after 7 days (Fig. 1). Gonadotropin-releasing hormone 1 (GnRH1) and gonadotropin-releasing hormone 2 (GnRH2) were injected on days 0 and 9, respectively. Both GnRH1 and GnRH2 contained $200 \mu \mathrm{g}$ of gonadorelin acetate (Fig.1).

\section{Blood sample collection from selected cows}

Blood from the jugular vein of each cow was collected using sterilized vacutainer mixed with an anticoagulant. Thirty blood samples were collected from $15 \mathrm{NC}$ group cows, before and after the estrous cycle of each. Another thirty blood samples were collected from 15 RB group cows, before and after the estrous cycle of each. Thus, a total of sixty blood samples were collected and preserved for biochemical analyses.

\section{Preparation of serum and biochemical tests}

Serum was prepared through centrifugation (1500 $\times \mathrm{g}$ for $20 \mathrm{~min}$ ) and preserved at $-20^{\circ} \mathrm{C}$ until further analysis. All the biochemical tests were performed using commercially available kits and reagents (Crescent Diagnostics, Jeddah, KSA). The analyses were carried out using a spectrophotometer (PD303S spectrophotometer, Japan). 


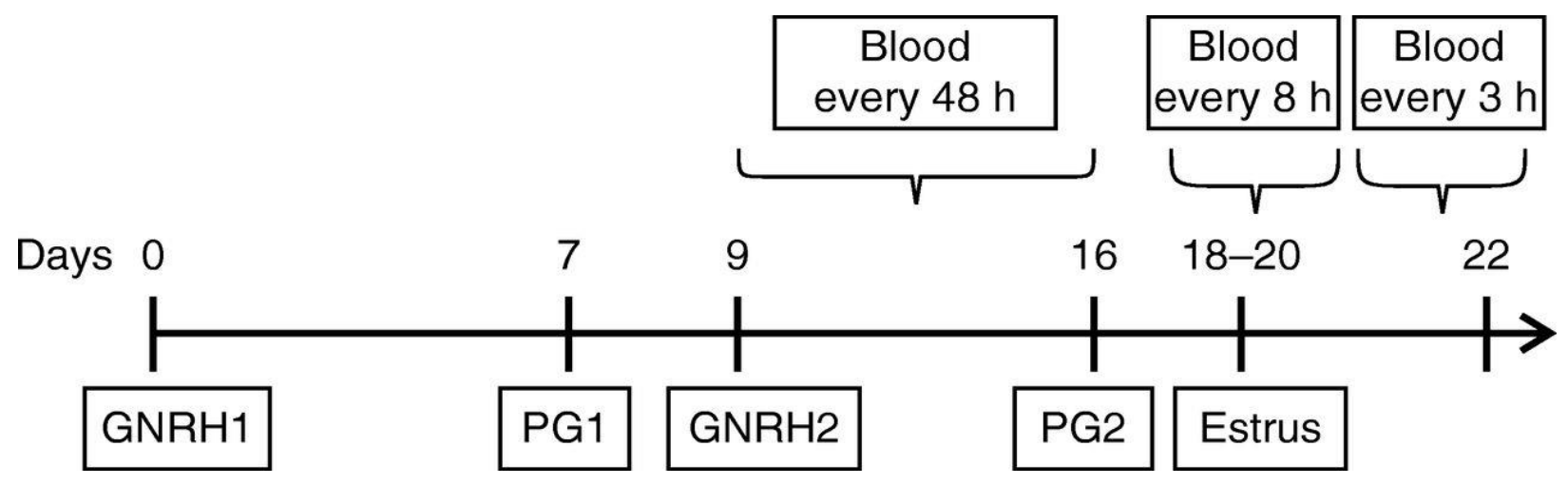

Fig. 1 Schematic representation of estrus synchronization, estrus detection, and bleeding schedule. GNRH = gonadotropin-releasing hormone; $\mathrm{PG}=$ prostaglandin.

\section{Statistical analysis}

Biochemical tests were performed in triplicate and the results are expressed as mean \pm SEM. Statistical analyses were performed using two-tailed students t-test, considering the confidence level at 5\% utilizing SPSS version 20 (SPSS Inc, Chicago, IL, USA).

\section{Results and Discussion}

As shown in Table 1, the mean level of luteinizing hormone in repeat breeder (RB) cows was 2.21 $\mathrm{mIU} / \mathrm{ml}$ while that in normal cyclic (NC) cows was $0.387 \mathrm{mIU} / \mathrm{ml}$. Thus, the level was significantly higher in RB than that of NC cows. The mean levels of follicle-stimulating hormone in $\mathrm{RB}$ and $\mathrm{NC}$ cows were $4.578 \mathrm{mIU} / \mathrm{ml}$ and $4.559 \mathrm{mIU} / \mathrm{ml}$, respectively. Thus, the follicle-stimulating hormone level was almost similar in two groups. The mean levels of prolactin in RB and NC cows were 0.565 $\mathrm{mIU} / \mathrm{ml}$ and $1.00 \mathrm{mIU} / \mathrm{ml}$, respectively. The level of human chorionic gonadotropin hormone was almost similar in both groups (NC $0.378 \mathrm{mIU} / \mathrm{ml}$ and $\mathrm{RB}$ $0.377 \mathrm{mIU} / \mathrm{ml}$ ). The present study investigated the plasma comparative hormonal profile of Bangladeshi selected NC and RB cows with regard to four hormones: follicle-stimulating hormone, luteinizing hormone, human chorionic gonadotropin hormone and prolactin. Among them, luteinizing hormone and prolactin differed significantly between the cows of two groups. Levels of both luteinizing hormone and folliclestimulating hormone have been reported to be increased in synchronized RB cows [6-8]. However, they did not notice any correlation between the luteinizing hormone level and conception. Our findings of LH and FSH levels in NC and RB cows are in accordance with those of Saleh et al. [9] and Barui et al. [10]. Increased levels of LH in the RB cows might be regulated by zinc and increased GnRH secretion by the hypothalamus [11]. Elevated luteinizing hormone and prolactin levels might be related to maintaining estrus behavior and reduced levels of ovarian progesterone and estradiol as well as stimulating follicular growth and ovulation [12].

Human chorionic gonadotropin possesses luteinizing hormone-like activity and aids in multifaceted effects in dairy cows, especially ovulation induction [13]. On ovarian cells, its effect is longer than those of luteinizing hormone and capable of acting independently of the pituitary gland. Thus, the level of human chorionic gonadotropin hormone could be manipulated in overcoming $\mathrm{RB}$ and other reproductive abnormalities. Our findings of different levels of prolactin in the $\mathrm{NC}$ and $\mathrm{RB}$ cows indicate a significant influence of this hormone in repeat

Table 1 Hormonal levels in normal cycle cows and repeat breeder cows.

\begin{tabular}{|c|c|c|c|}
\hline Parameters & $\begin{array}{c}\text { Normal cyclic cows } \\
\text { Mean } \pm \text { SE }\end{array}$ & $\begin{array}{c}\text { Repeat breeder cows } \\
\text { Mean } \pm \text { SE }\end{array}$ & Level of significance \\
\hline Luteinizing hormone (mIU/ml) & $0.387 \pm 0.008$ & $2.210 \pm 0.471$ & $* * *$ \\
\hline FSH $(\mathrm{mIU} / \mathrm{ml})$ & $4.559 \pm 0.128$ & $4.578 \pm 0.063$ & NS \\
\hline Prolactin $(\mathrm{mIU} / \mathrm{ml})$ & $1.000 \pm 0.172$ & $0.565 \pm 0.044$ & $* *$ \\
\hline $\mathrm{hCG}(\mathrm{mIU} / \mathrm{ml})$ & $0.377 \pm 0.084$ & $0.378 \pm 0.007$ & NS \\
\hline
\end{tabular}

$\mathrm{SE}=$ standard error; $* * *=$ highly significant $; * *$ significant NS $=$ non-significant $; \mathrm{FSH}=$ follicle stimulating hormone; hCG $=$ human chorionic gonadotropin 
breeding problems. Our findings are different from those of Tong et al. [14]. Prolactin stimulates lactation in the mammary glands and their level increases at the end of pregnancy in an inverse relationship with progesterone glands [14]. The findings of the current study would shed light on strategizing measures against repeat breeding problems and thus aid in maintaining the normal reproductive life of the dairy cows to curtailing economic loss of the nation.

\section{Conclusion}

Luteinizing hormone was found significantly higher in the serum of the repeat breeder cows and prolactin was found significantly higher in the serum of normal cyclic cows. While the levels of follicle-stimulating hormone and human chorionic gonadotropin hormone did not vary significantly between the cow groups, they might have fewer implications in repeat breeding problems. The current findings of Bangladeshi normal cyclic and repeat breeder cows would aid in formulating strategies against repeat breeding problems at home and abroad.

\section{Conflict of interest}

The authors declare no conflict of interest.

\section{Acknowledgment}

The authors are grateful to Jahangirnagar University, Bangladesh and Bangladesh Livestock Research Institute for providing financial and instrumental support.

\section{References}

[1] Nussey S, Whitehead S. Endocrinology: An Integrated Approach. Oxford: BIOS Scientific Publishers; 2001.

[2] Islam MS, Ali MY, Zama ME, Khatun R, Yousuf MA, Alam MA, et al. Study on the hormonal profile in crossbred dairy cows in relation to repeat breeding at Baghabari milk shed areas, Bangladesh. Asian Australas J Biosci Biotechnol 2018; 3(3):237-240.
[3] Asaduzzaman KM, Bhuiyan MMU, Rahman MM, Bhattacharjee J. Prevalence of repeat breeding and its effective treatment in cows at selected areas of Bangladesh. Bangl J Vet Med 2016; 14(2):183-190.

[4] Tiwari I, Shah R, Kaphle K, Gautam M. Treatment approach of different hormonal therapy for repeat breeding dairy animals in Nepal. Arch Vet Sci Med 2019; 2(3):28-40.

[5] Nowicki A, Barański W, Baryczka A, Janowski T. OvSynch protocol and its modifications in the reproduction management of dairy cattle herds - an update. J Vet Res 2017; 61(3):329-336.

[6] Ahmed R, Tasnim M, Halim MA, Sarker M, Islam S, Morshed MM. A Comparative study on reproductive hormones of repeat breeding and synchronized repeat breeding dairy cows under bathan rearing system at Baghabari milk shed areas in Bangladesh. ISOR J Agril Vet Sci 2018; 11(11):55-60.

[7] Tasnim M, Ahammed R, Kham MMAS, Hasan Ashraful, Islam MS, Morshed M. A comparative study on lipid profile of before and after synchronized dairy cows under bathan rearing system at Sirajgonj district of Bangladesh. Int J Biosci 2018; 13(5):301308.

[8] Lee CN, Critser JK, Ax RL. Changes of luteinizing hormone and progesterone for dairy cows after gonadotropin-releasing hormone at first postpartum breeding. J Dairy Sci 1985; 68(6):1463-1470.

[9] Saleh N, Mahmud E, Waded E. Interactions between insulin like growth factor 1, thyroid hormones and blood energy metabolites in cattle with postpartum inactive ovaries. Nat Sci 2011; 9(5):56-63.

[10] Barui A, Batabyal S, Ghosh S, Saha D, Chattopadhyay S. Plasma mineral profiles and hormonal activities of normal cycling and repeat breeding crossbred cows: A comparative study. Vet World 2015; 8(1):42-45.

[11] Kaswan S, Bedwal RS. Light and electron microscopic changes in the ovary of zinc deficient BALB/c mice. Ind J Exp Biol 1995; 33(7):469-479.

[12] Sood P, Zachut M, Dube H, Moallem U. Behavioral and hormonal pattern of repeat breeder cows around estrus. Reproduction 2015; 149(6):545-554.

[13] De Rensis F, López-Gatius F, García-Ispierto I, Techakumpu M. Clinical use of human chorionic gonadotropin in dairy cows: an update. Theriogenology 2010; 73(8):1001-1008.

[14] Tong JJ, Thompson IM, Zhao X, Lacasse, P. Effect of the concentration of circulating prolactin on dairy cows' responsiveness to domperidone injection. J Dair Sci 2018; 101(3):2579-2587. 